\title{
Intragenic CpG Islands and Their Impact on Gene Regulation
}

\author{
James A. Cain ${ }^{\dagger}$, Bertille Montibus ${ }^{\dagger}$ and Rebecca J. Oakey ${ }^{\star \dagger}$ \\ Department of Medical and Molecular Genetics, King's College London, Guy's Hospital, London, United Kingdom
}

The mammalian genome is depleted in CG dinucleotides, except at protected regions where they cluster as CpG islands (CGIs). CGls are gene regulatory hubs and serve as transcription initiation sites and are as expected, associated with gene promoters. Advances in genomic annotations demonstrate that a quarter of CGls are found within genes. Such intragenic regions are repressive environments, so it is surprising that CGls reside here and even more surprising that some resist repression and are transcriptionally

OPEN ACCESS

Edited by:

Robert Feil,

UMR5535 Institut de Génétique Moléculaire de Montpellier (IGMM),

France

Reviewed by:

Maxim Van Cleef Greenberg, UMR7592 Institut Jacques Monod (IJM), France

*Correspondence:

Rebecca J. Oakey rebecca.oakey@kcl.ac.uk

'ORCID ID:

James A. Cain, orcid.org/0000-0001-8141-0666 Bertille Montibus, orcid.org/0000-0002-6895-3954 Rebecca J. Oakey, orcid.org/0000-0003-2706-8139

Specialty section:

This article was submitted to Developmental Epigenetics, a section of the journal Frontiers in Cell and Developmental Biology

Received: 09 December 2021 Accepted: 20 January 2022 Published: 11 February 2022

Citation: Cain JA, Montibus B and Oakey RJ (2022) Intragenic CpG Islands and Their Impact on Gene Regulation. Front. Cell Dev. Biol. 10:832348. doi: 10.3389/fcell.2022.832348 active within a gene. Hence, intragenic CGl positioning within genes is not arbitrary and is instead, selected for. As a wealth of recent studies demonstrate, intragenic CGls are embedded within genes and consequently, influence 'host' gene mRNA isoform length and expand transcriptome diversity.

Keywords: polyadenylation, epigenetics, DNA methylation, orphan CpG-Islands, CpG island (CGI), alternative polyadenylation (APA), mRNA processing

\section{INTRODUCTION}

Gene regulation is a prerequisite of life, the seemingly simple decision of whether to express a gene or not is present in nearly all organisms. Regulatory elements are sequence specific motifs in the mammalian genome that coordinate gene expression. One fundamental class of regulatory element are the $\mathrm{CpG}$ islands (CGIs). CGIs are regions of the genome that are enriched for cytosine and guanine dinucleotides (CpGs) and have been defined bioinformatically as having a GC content over $50 \%$, an observed CpG ratio compared to the whole genome (Obs/Exp) of over 0.6 and a length of over 200 bps (Gardiner-Garden and Frommer, 1987) (Figure 1A). CpG's in isolation are modified with DNA methylation, the addition of a methyl group onto cytosine, which is a heritable epigenetic mark. However, when CpGs congregate into islands they are generally protected from DNA methylation (Bird, 1978; Bird et al., 1979; Bird et al., 1985).

Instances where CGIs are DNA methylated have been correlated with transcriptional silencing when they are in close proximity to transcription start sites (TSS) of genes (Deaton and Bird, 2011). Using bioinformatic criteria, most CGIs are indeed found at TSSs, but this does not take into account their biochemical potential to exhibit or lack DNA methylation (Larsen et al., 1992; Takai and Jones, 2002; Saxonov et al., 2006). To overcome this, methods that specifically enrich for DNA fragments containing CGIs, with and without DNA methylation, were developed and combined with next generation sequencing to biochemically detect CGI coordinates (Illingworth et al., 2008; Blackledge et al., 2012) (Figure 1B). These studies found that only half of CGIs in mouse and human genomes are associated with TSS of genes and the rest are unannotated "orphans", that are located either distal to genes (intergenic) or within genes themselves (intragenic) (Figure 1C). Not only are these "orphan" CGIs more likely to be DNA methylated (Figure 1C), but they are also more likely to demonstrate DNA methylation and transcriptional signatures in a tissue-specific manner (Illingworth et al., 2010; Deaton et al., 
A

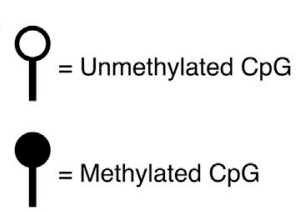

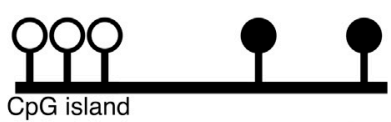

GC content over $50 \%$ Obs/Exp CpG > 0.6 $>200 b p s$ Length
B

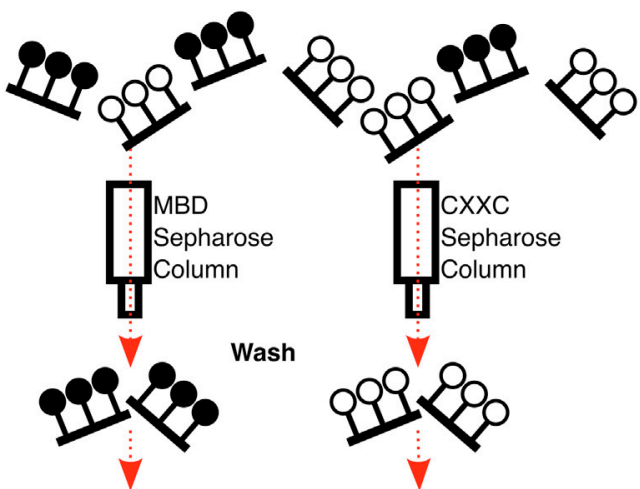

Next Generation Sequencing

C

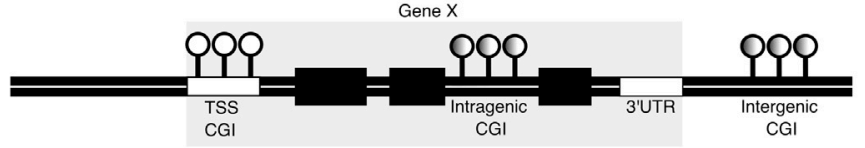

Total Number and Methylation Status of CGIs in Mouse and Human As reported by Illingworth et al 2010

\begin{tabular}{l|rrr}
\multicolumn{5}{c}{ As reported by llingworth et al 2010 } \\
\hline \multicolumn{5}{c}{ CGI Count } & \% of Total & \% Methylated in Somatic Tissues \\
\hline Mouse & & & \\
\hline TSS & 11,932 & $51.8 \%$ & $2.4 \%$ \\
\hline Intragenic & 5,628 & $24.4 \%$ & $13.0 \%$ \\
\hline Intergenic & 5,461 & $23.7 \%$ & $2.8 \%$ \\
\hline Human & & & $21.5 \%$ \\
\hline TSS & 12,278 & $48.2 \%$ & $14.3 \%$ \\
\hline Intragenic & 6,376 & $25.0 \%$ &
\end{tabular}

D
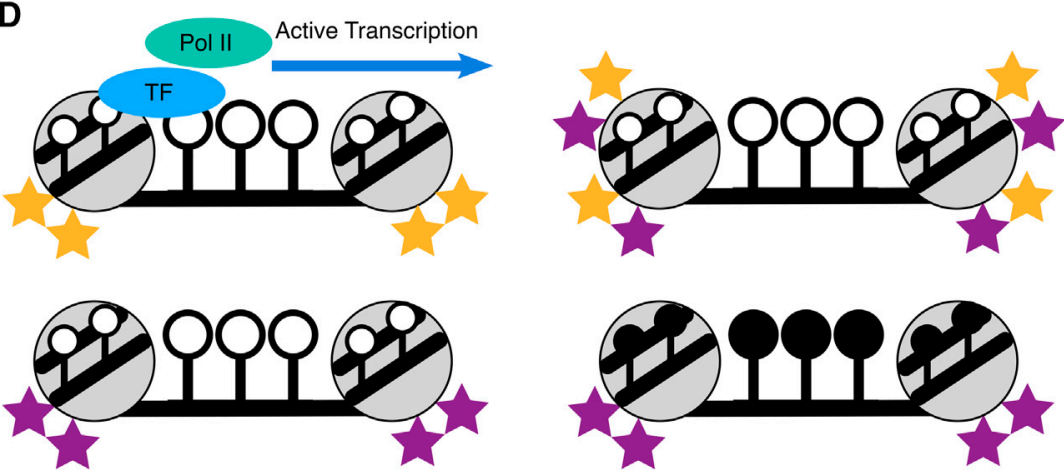

$=\mathrm{H} 3 \mathrm{~K} 4 \mathrm{me} 3$

$Y=$

$=\mathrm{H} 3 \mathrm{~K} 27 \mathrm{me} 3$
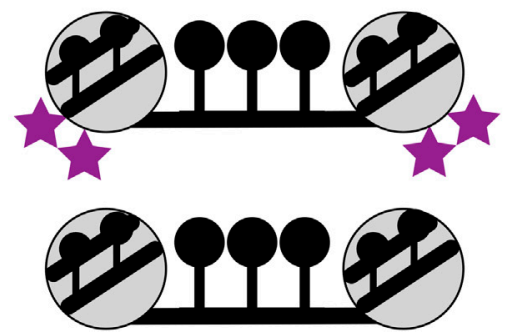

FIGURE 1 Definitions and states of CpG islands. (A) Depiction of the typical CpGs in the mammalian genome which are DNA methylated in isolation but are devoid of this mark in the CGI context. CGls were originally defined bioinformatically. (B) Schematic demonstrating CGls locations were biochemically determined. MBD and CXXC proteins fixed to a Sepharose column allowed purification of DNA methylated and unmethylated CGls in mammals. (C) Representation of CGIs across mammalian genomes and a table, summarising the proportion and methylation status of CGls as reported by llingworth et al. (2010) in mouse and human across TSS, Intragenic and Intergenic regions. Total CGI numbers in mouse $=23,021$, human $=25,495$ (D) Summary of the main states of CGls across the genome. Their active state is associated with binding of transcription factors (TF) and subsequent RNA Polymerase II (Pol II) binding. Repressed states of CGls are through combinations of DNA methylation, $\mathrm{H} 3 \mathrm{~K} 4 \mathrm{me} 3$ and $\mathrm{H} 3 \mathrm{~K} 27 \mathrm{me} 3$.

2011). Intragenic CGIs (iCGIs) are particularly striking as they are embedded within genes across mammalian species and are often not considered by most analyses, which use the standard bioinformatic definition of CGIs.
iCGIs can impact gene expression in a multitude of ways either by being transcriptionally active themselves or through interactions with biological processes in close vicinity. Biochemical methods discovered that a quarter of all CGIs are 
within genes, existing as iCGIs. Recent studies have now tied iCGIs to multiple functions (Maunakea et al., 2010; Jeziorska et al., 2017; Amante et al., 2020). Comprehensive reviews discuss CGIs more broadly and in the context of development and disease (Deaton and Bird, 2011; Greenberg and Bourc'his, 2019). This minireview aims to update the current knowledge of CGIs and capture their repertoire of functions outside of canonical TSSs.

\section{CGIS ARE PROMOTERS INDEPENDENT OF GENOMIC POSITION}

Chromatin, the complex of DNA and histone proteins which forms chromosomes, can exist in an open or closed configuration indicative of active or inactive gene expression. The state of chromatin across the mammalian genome is studied through analysis of histone tail modifications, marking the histones that DNA is wrapped around. Over 100 histone modifications exist, some are well understood and some remain enigmatic, without a known biological function (Zhao and Garcia, 2015). Still, histone modifications are correlated to states of chromatin and are invaluable markers when studying gene regulation. CGIs overlap with $>70 \%$ of canonical TSSs in the human genome and are typically associated with promoters (Saxonov et al., 2006), where they can exhibit multiple states, referred to here as 'CGI states'. These states can be categorised depending on their histone marks.

One state is bivalency, where CGIs are transcriptionally repressed, devoid of DNA methylation and exhibit both active histone 3 lysine 4 trimethylation ( $\mathrm{H} 3 \mathrm{~K} 4 \mathrm{me} 3$ ) and repressive histone 3 lysine 27 trimethylation (H3K27me3) modifications. Bivalency has been proposed to poise CGI promoters for activation (Bernstein et al., 2006; Voigt et al., 2013), but has more recently been suggested to protect CGIs from DNA methylation whilst simultaneously keeping them transcriptionally inactive (Maupetit-Méhouas et al., 2016; Kumar and Jothi, 2020; Shah et al., 2021). The majority of promoter associated CGIs across the human genome exhibit bivalency (Court et al., 2019). This state likely arises due to the sequence composition of CGIs rather than their location, as CGIs experimentally introduced into the $\beta$-globin locus in mouse embryonic stem cells also displayed bivalency (Krebs et al., 2014; Wachter et al., 2014). The shift from bivalent CGIs to active CGIs is initiated through the binding of transcription factors, leading to the removal of $\mathrm{H} 3 \mathrm{~K} 27 \mathrm{me} 3$, whilst maintaining the $\mathrm{H} 3 \mathrm{~K} 4 \mathrm{me} 3$ mark. Removal of H3K4me3 and maintenance of H3K27me3 at the CGI is repressive, otherwise known as polycomb-only mediated repression, and is observed at a minority of promoter CGIs in somatic tissues (Mikkelsen et al., 2007; Farcas et al., 2012; Court et al., 2019; Blackledge et al., 2020).

A more stable form of repression at CGIs is through DNA methylation. In somatic tissues, DNA methylation represses promoter CGIs at the inactivated X chromosome (Augui et al., 2011; Galupa and Heard, 2018), germline genes (Velasco et al., 2010; Dahlet et al., 2021; Mochizuki et al., 2021), imprinted genes (Barlow and Bartolomei, 2014), and some lineage-committed genes (Dahlet et al., 2020). Whilst H3K27me3 and DNA methylation are both repressive, they are typically mutually exclusive at CGIs (Brinkman et al., 2012; Statham et al., 2012). Chromatin immunoprecipitation experiments indicate that H3K27me3 and DNA methylation can co-exist at some imprinted genes (Maupetit-Méhouas et al., 2016). CGIs can therefore exhibit multiple states of chromatin which are indicative of their transcriptional potential (Blackledge and Klose, 2011) (Figure 1D).

iCGIs are more likely to be DNA methylated (Figure 1C) and those lacking DNA methylation can exhibit bivalent chromatin signatures and when transcriptionally active, show transcription factor binding and the promoter mark, H3K4me3 (Lee et al., 2017; Amante et al., 2020; Choi et al., 2020). iCGIs can therefore exist in the same 'states' as promoter CGIs, albeit in different proportions. The iCGI states themselves are regulated in a tissuespecific manner, and with crosstalk from the gene that 'hosts' them. This can lead to both, consequences on the iCGI itself and their corresponding host gene.

\section{CONSEQUENCES OF BEING AN INTRAGENIC CGI WITHIN A GENE}

The location of iCGIs within a gene is a turbulent place for a promoter region because active transcription results in the silencing of DNA which has been transcribed through. At first, this sounds paradoxical, but it has been identified at various loci that transcription through a gene promoter can silence it. This phenomenon was first demonstrated at the $\alpha$ globin locus in a case of a-thalassemia where the $L U C 7 L$ gene is juxtaposed upstream of HBA2. Here, LUC7L transcription extends through the HBA2 promoter CGI which is subsequently DNA methylated and silenced (Tufarelli et al., 2003). This can be observed naturally at regions of genes that contain clusters of overlapping genes, such as at the imprinted loci, Gnas and Igfr2 and likely, at Kncq1 too. At the Gnas locus, incoming transcription from upstream Nesp removes H3K4me3 at the Gnas CGI and establishes DNA methylation and silencing (Chotalia et al., 2009; Williamson et al., 2011). Transcription of the Airn long non-coding RNA (lncRNA) through the Igfr2 promoter silences Igfr2 (Latos et al., 2012; Santoro et al., 2013). Similarly, the Kcnq1 locus contains an overlapping transcript, Kcnq1ot1, that overlaps with the Kcnq1 CGI promoter. Silencing of Kcnq1 is correlated to transcription of the overlapping Kcnq1ot1, suggesting transcription itself is causing gene repression (Golding et al., 2011). Genome-wide analysis now highlights that this repression is through interactions between the transcribing RNA Polymerase II and the deposition of the elongation associated histone mark, H3K36me3. This in turn recruits DNMT3B, to deposit de novo intragenic DNA methylation (Baubec et al., 2015; Neri et al., 2017; Dahlet et al., 2020) (Figure 2A).

This may indicate that tissue-specific patterns of DNA methylation at iCGIs are a by-product of transcription through the gene itself, where iCGI function as a promoter is silenced when the host gene is transcriptionally active. Whilst iCGIs hosted within an active gene are generally 


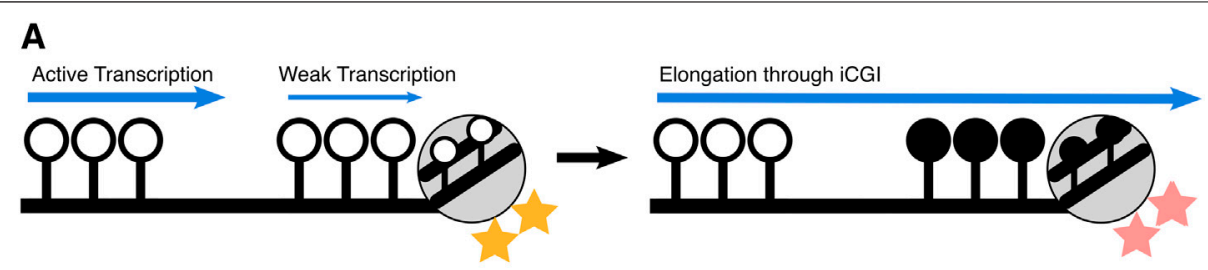

B Transcriptional interference upstream of iCGI

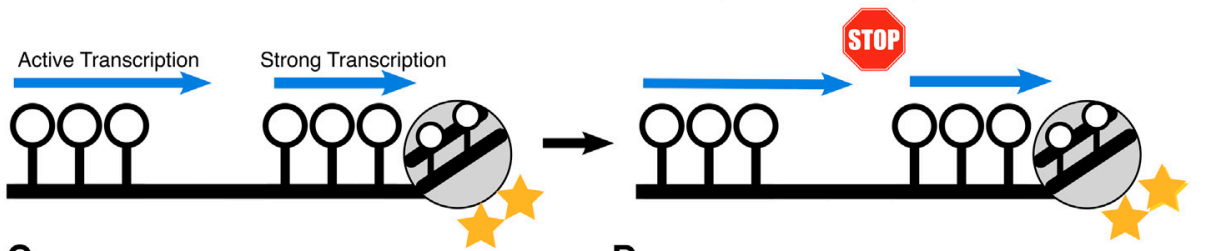

C

D
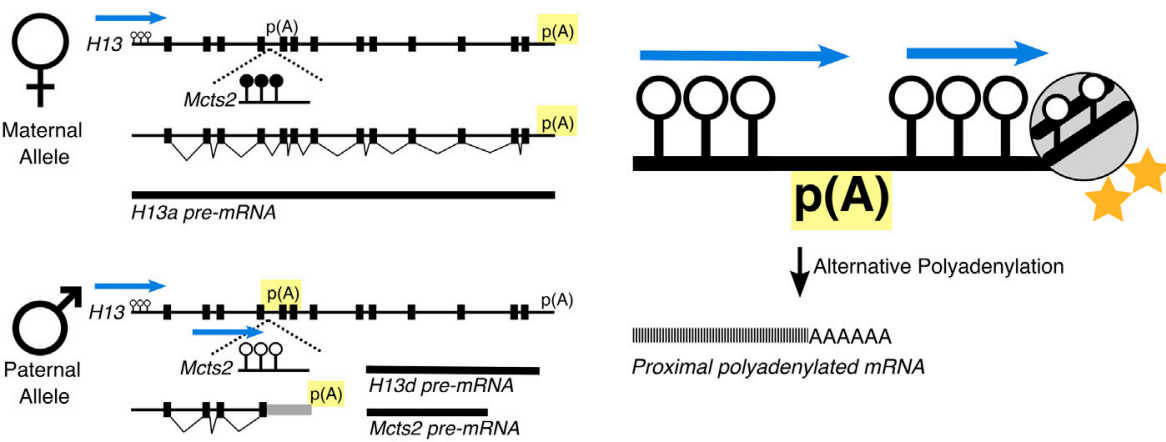

$\downarrow$ Alternative Polyadenylation

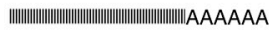

Proximal polyadenylated $m R N A$

$\mathbf{E}$

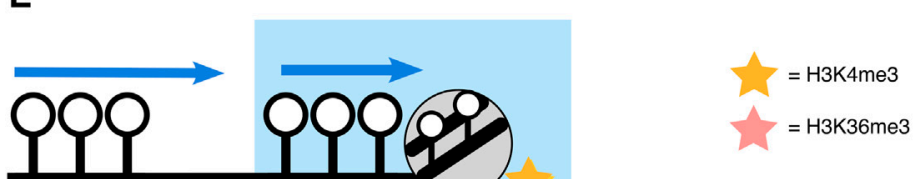

Gene X Promoter

CGI

\begin{tabular}{|lr|}
\hline Alternative & Promoter for \\
promoter for & Gene $Y$ \\
Gene $X$ &
\end{tabular}

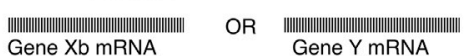

FIGURE 2 | Schematics of how iCGls impact gene regulation mechanisms. (A) Transcription through a 'weak' iCGI can silence it, depositing H3K36me3 and DNA methylation at the iCGI. (B) However, if the iCGI exhibits strong transcriptional activity, it can lead to transcriptional interference. This can result in events akin to those at the (C) H13/Mcts2 locus, that exhibits allele-specific PAS usage. Usage of the PAS is highlighted in yellow. (D) Similar mechanisms have been found other iCGls. Alternatively, and in some cases, simultaneously, (E) the iCGI can act as a promoter itself, highlighted in blue, for either the host gene itself (gene X) or for a different 'nested' gene (gene Y).

silenced, subsets of iCGIs that show more RNA Polymerase II binding are protected from this silencing and maintain their H3K4me3 promoter status (Jeziorska et al., 2017). This indicates that iCGIs can resist the silencing power of transcription, but only if they are 'strong' enough to do so (Figures 2A,B).

What are the factors that dictate CGI strength? There is speculation that long CGIs may exhibit more sites for RNA Polymerase II binding (Elango and Yi, 2011) and a higher CpG density is correlated to enhanced transcription factor binding (Hartl et al., 2019). Given that iCGIs are generally shorter than promoter CGIs and less CpG dense, this may explain why a subset of iCGIs are silenced. But, despite this, subsets of iCGIs escape transcriptional silencing and this can have a series of effects on the host gene itself.

\section{CONSEQUENCES ON THE GENE FOR HOSTING AN ACTIVE INTRAGENIC CGI}

Polyadenylation and splicing are co-transcriptional processes that can generate a diversity of mature mRNA isoforms from a single gene. Briefly, regulation of splicing and polyadenylation can control which exons of the pre-mRNA are utilised and when 
the pre-mRNA should be terminated. Alternative regulation of either of these processes impact the function of the mature mRNA (Proudfoot, 2011; Lee and Rio, 2015) and both recruit large protein machineries that regulate these processes cotranscriptionally (Lee and Rio, 2015; Tian and Manley, 2016; Gruber and Zavolan, 2019). As such, it seems plausible that iCGI activity can impact splicing and polyadenylation when they are co-occurring in close proximity.

Coincidentally, there are a wealth of studies linking active iCGIs to alternative polyadenylation (APA) events, specifically intronic APA (iAPA), which can alter the protein coding sequence of mRNA transcripts as it is terminated prematurely. This was first demonstrated at the imprinted Mcts $2 / H 13$ locus (Wood et al., 2008). Here, H13 isoforms are alternatively polyadenylated depending on the parental origin of DNA methylation at the iCGI within H13's fifth intron. This iCGI is a promoter for a nested gene, Mcts2 and when active (paternal allele), polyadenylation of $\mathrm{H} 13$ occurs within intronic regions. However, when Mcts2 and its iCGI promoter are silenced (maternal allele), polyadenylation occurs at the $3^{\prime} \mathrm{UTR}$ of $\mathrm{H} 13$ (Figure 2C). This mechanism of APA is the same at the imprinted Nap1l5/Herc3 locus. Here, an iCGI is a promoter for Nap1l5 and its parental origin is correlated with the polyadenylation site choice of the host gene, Herc3 (Cowley et al., 2012).

Outside of the imprinted context, two recent studies which perturbed DNA methylation showed similar results at iCGIs. Knockout of DNA methyltransferases (DNMT1 \& DNMT3B) in cancer cells increased initiating RNA Polymerase II at the iCGI which was correlated with the usage of proximal polyadenylation sites of two host genes (Nanavaty et al., 2020). Similar polyadenylation site usage was also found when DNA methylation was perturbed at the iCGI within the NFATc1 locus, resulting in alternative NFATc1 isoforms. These locus specific effects have been detected genome-wide by a recent bioinformatic screen, emphasising that iCGI activity leads to premature transcription termination upstream of the iCGI, most likely through APA (Amante et al., 2020) (Figures 2B,D).

These findings demonstrate that a transcriptionally active iCGI can influence alternative polyadenylation and highlight the ways in which iCGIs can shape the transcriptome. Mechanistically, this is likely due to RNA polymerase II prematurely stopping because of meeting another initiating polymerase at the iCGI, otherwise known as transcriptional interference (TI) (Shearwin et al., 2005) (Figure 2B). Here, the polyadenylation machinery selects the nearest site to avoid the production of an unstable mRNA transcript. It is still undetermined whether iCGI activity influences APA serendipitously through $\mathrm{TI}$, or if this is a direct mechanism to regulate pre-mRNA termination.

An active iCGI can also influence isoform choice more directly, by acting as an alternative promoter for the host gene (Figure 2D). The SHANK3 gene for example, contains an iCGI which is differentially methylated between hippocampus and cortex astrocytes. In hippocampus astrocytes, the iCGI is active and devoid of DNA methylation where it serves as an alternative promoter for $S H A N K 3$, transcribing a shorter mRNA transcript.
Whereas in cortex astrocytes, when the iCGI is silenced through DNA methylation and instead, the canonical full length SHANK3 isoform is transcribed (Maunakea et al., 2010).

\section{CGI FUNCTION AS ENHANCER REGIONS}

Recent work suggests that CGIs may have another regulatory role as enhancers. Enhancers are cis-regulatory 50-150bp DNA sequences that are characterised by enriched transcription factor binding sites, $\mathrm{H} 3 \mathrm{~K} 4 \mathrm{mel}$ and $\mathrm{H} 3 \mathrm{~K} 27 \mathrm{ac}$ histone modifications and when active, regions of bidirectional transcription produce enhancer RNAs (eRNAs) (Kim et al., 2010; Santa et al., 2010; Li et al., 2016). eRNAs confer cisregulatory effects by recruiting transcriptional machinery to target genes to induce gene activation (Arner et al., 2015), otherwise referred to as enhancer looping. Intragenic enhancers can interfere with host gene expression through transcriptional interference (Onodera et al., 2012; Cinghu et al., 2017), similar to active iCGIs. Bioinformatic analyses show that iCGIs themselves exhibit enhancer histone modifications, are actively transcribed to eRNAs, are conserved across mammalian species (Bell and Vertino, 2017) and show greater transcription factor binding (Steinhaus et al., 2020). Such signatures have been identified at an iCGI within $K d m 6 b$, which exhibits H3K4me1 and loops to the promoter CGI to enhance $K d m 6 b$ expression (Montibus et al., 2021). Given that transcription of enhancer regions is required to deposit enhancer histone marks, it is unclear how CGIs are initially defined as enhancer regions (Kaikkonen et al., 2013).

Enhancer signatures are also found at the other type of 'orphan' CGI, intergenic CGIs. A recent study has challenged the idea that these CGIs directly serve as enhancers, and instead, boost proximal enhancer function (Pachano et al., 2021). Here, intergenic CGIs augment enhancers' ability to amplify only target genes that contain a CGI promoter themselves. As enhancers loop to promoter CGIs, the unmethylated intergenic CGIs that are within $3 \mathrm{~kb}$ of the proximal enhancer bring along machinery for efficient promoter CGI transcription. These intergenic CGIs also serve to protect transcription factor binding sites (TFBS) within the proximal enhancer from repressive DNA methylation (Pachano et al., 2021). The relationship between intergenic CGIs and proximal enhancers may be reciprocal, as the TFBS within the enhancer can assist recruitment of machinery to the intergenic CGI itself.

\section{CONCLUSIONS, THE RELEVANCE OF INTRAGENIC CGIS IN BIOLOGY}

CGIs are regions where transcription can initiate. Whilst most CGIs are localised to annotated TSSs, many can be found intragenically. In some cases, the iCGI is silenced; in others, active iCGIs impact pre-mRNA processing and promote or contain enhancer function.

iCGIs are more prone to DNA methylation during embryonic development and adult development compared to their TSS CGI 
counterparts (Illingworth et al., 2010; Auclair et al., 2014), implying that regulation of iCGIs is crucial for tissue specific programming. For example, iCGIs are specifically expressed in brain tissues and their host genes function in brain-specific biological processes (Amante et al., 2020). In this case, iCGIs may function as TSSs for novel transcripts or result in APA of the host gene and therefore, expand the transcriptome during developmental processes such as neurogenesis. iCGIs are conserved across mammalian species (Illingworth et al., 2010), suggesting they are maintained and necessary for proper gene regulation. It is still unclear how the multitude of functionalities of iCGIs are specified, i.e., how does an iCGI know to serve as an alternative promoter or, to disrupt host gene polyadenylation.

Similarly, DNA methylation of iCGIs prevents spurious intragenic transcription (Neri et al., 2017; Dahlet et al., 2020). Blocking spurious intragenic transcriptional activity is a method to ensure productive elongation by RNA polymerase II. DNA hypomethylation is widespread in cancer cells and extends to intragenic regions (Ehrlich, 2002; Hon et al., 2012; Kulis et al., 2012), hinting that intragenic transcription may be widespread in cancer (Kulis et al., 2013). The RB1 gene, for example, contains an imprinted iCGI where its DNA methylation is inversely correlated to expression of the full length $R B 1$ transcript (Kanber et al., 2009; Kulis et al., 2012). The region which contains the iCGI is commonly deleted in cases of chronic lymphocytic leukaemia, implying that iCGIs may be disrupted in cancer cells. Despite this, intragenic DNA hypomethylation in cancer is mainly outside of promoter CGIs and they are paradoxically, hypermethylated instead (Kulis et al., 2013; Court et al., 2019). It is currently unknown if the cancer signature of hypomethylation extends to iCGIs, or if they are hypermethylated like promoter CGIs and if this is functionally relevant.

Given their distinct regulation and that many are protected from DNA methylation it is reasonable to suggest that iCGIs are

\section{REFERENCES}

Amante, S. M., Montibus, B., Cowley, M., Barkas, N., Setiadi, J., Saadeh, H., et al. (2020). Transcription of Intragenic CpG Islands Influences Spatiotemporal Host Gene Pre-mRNA Processing. Nucleic Acids Res. 48, 8349-8359. doi:10. 1093/nar/gkaa556

Arner, E., Daub, C. O., Vitting-Seerup, K., Andersson, R., Lilje, B., Drabløs, F., et al. (2015). Transcribed Enhancers lead Waves of Coordinated Transcription in Transitioning Mammalian Cells. Science 347, 1010-1014. doi:10.1126/science. 1259418

Auclair, G., Guibert, S., Bender, A., and Weber, M. (2014). Ontogeny of CpG Island Methylation and Specificity of DNMT3 Methyltransferases during Embryonic Development in the Mouse. Genome Biol. 15, 545. doi:10.1186/s13059-0140545-5

Augui, S., Nora, E. P., and Heard, E. (2011). Regulation of X-Chromosome Inactivation by the X-Inactivation centre. Nat. Rev. Genet. 12, 429-442. doi:10.1038/nrg2987

Barlow, D. P., and Bartolomei, M. S. (2014). Genomic Imprinting in Mammals. Cold Spring Harbor Perspect. Biol. 6, a018382. doi:10.1101/cshperspect.a018382

Baubec, T., Colombo, D. F., Wirbelauer, C., Schmidt, J., Burger, L., Krebs, A. R., et al. (2015). Genomic Profiling of DNA Methyltransferases Reveals a Role for DNMT3B in Genic Methylation. Nature 520, 243-247. doi:10.1038/ nature 14176 required in mammalian biology. A clear challenge that has limited our understanding of iCGIs is their overlap with genomic annotations. Conventional short-read sequencing technologies present a challenge when trying to distinguish whether signals or reads stem from the host gene or the iCGI. The arrival of long-read sequencing technologies and the eventual decline in cost of such methods will allow these reads to be distinguished and aid understanding of iCGIs (Logsdon et al., 2020). This will further be enhanced by studying the methylation of iCGIs in more contexts, which will be possible when methods such as whole-genome bisulphite sequencing (WGBS) are more cost effective. Technology in its current state can also aid understanding of iCGIs, with greater reporting of genomic locations of CGIs in genome-wide analyses of DNA methylation, which are currently skewed to canonical TSSs.

\section{AUTHOR CONTRIBUTIONS}

JC wrote and composed the paper, BM and RO provided supervision and contributed significantly to the final version of the paper.

\section{FUNDING}

JC is supported by the UK Medical Research Council MR/ N013700/1 and King's College London and is a member of the MRC Doctoral Training Partnership in Biomedical Sciences.

\section{ACKNOWLEDGMENTS}

We are extremely grateful to Hannah Mischo and Lisa Dressler for their insightful and useful comments on the review.

Bell, J. S. K., and Vertino, P. M. (2017). Orphan CpG Islands Define a Novel Class of Highly Active Enhancers. Epigenetics 12, 449-464. doi:10.1080/15592294. 2017.1297910

Bernstein, B. E., Mikkelsen, T. S., Xie, X., Kamal, M., Huebert, D. J., Cuff, J., et al. (2006). A Bivalent Chromatin Structure Marks Key Developmental Genes in Embryonic Stem Cells. Cell 125, 315-326. doi:10.1016/j.cell.2006. 02.041

Bird, A. P., Taggart, M. H., and Smith, B. A. (1979). Methylated and Unmethylated DNA Compartments in the Sea Urchin Genome. Cell 17, 889-901. doi:10.1016/ 0092-8674(79)90329-5

Bird, A., Taggart, M., Frommer, M., Miller, O. J., and Macleod, D. (1985). A Fraction of the Mouse Genome that Is Derived from Islands of Nonmethylated, CpG-Rich DNA. Cell 40, 91-99. doi:10.1016/0092-8674(85)90312-5

Bird, A. P. (1978). Use of Restriction Enzymes to Study Eukaryotic DNA Methylation. J. Mol. Biol. 118, 49-60. doi:10.1016/0022-2836(78)90243-7

Blackledge, N. P., and Klose, R. (2011). CpG Island Chromatin. Epigenetics 6, 147-152. doi:10.4161/epi.6.2.13640

Blackledge, N. P., Long, H. K., Zhou, J. C., Kriaucionis, S., Patient, R., and Klose, R. J. (2012). Bio-CAP: a Versatile and Highly Sensitive Technique to Purify and Characterise Regions of Non-methylated DNA. Nucleic Acids Res. 40, e32. doi:10.1093/nar/gkr1207

Blackledge, N. P., Fursova, N. A., Kelley, J. R., Huseyin, M. K., Feldmann, A., and Klose, R. J. (2020). PRC1 Catalytic Activity Is Central to Polycomb System Function. Mol. Cel 77, 857-874. doi:10.1016/j.molcel.2019.12.001 
Brinkman, A. B., Gu, H., Bartels, S. J. J., Zhang, Y., Matarese, F., Simmer, F., et al. (2012). Sequential ChIP-Bisulfite Sequencing Enables Direct Genome-Scale Investigation of Chromatin and DNA Methylation Cross-Talk. Genome Res. 22, 1128-1138. doi:10.1101/gr.133728.111

Choi, W.-Y., Hwang, J.-H., Cho, A.-N., Lee, A. J., Lee, J., Jung, I., et al. (2020). DNA Methylation of Intragenic CpG Islands Are Required for Differentiation from iPSC to NPC. Stem Cel Rev. Rep. 16, 1316-1327. doi:10.1007/s12015-02010041-6

Chotalia, M., Smallwood, S. A., Ruf, N., Dawson, C., Lucifero, D., Frontera, M., et al. (2009). Transcription Is Required for Establishment of Germline Methylation marks at Imprinted Genes. Genes Dev. 23, 105-117. doi:10. 1101/gad.495809

Cinghu, S., Yang, P., Kosak, J. P., Conway, A. E., Kumar, D., Oldfield, A. J., et al. (2017). Intragenic Enhancers Attenuate Host Gene Expression. Mol. Cel 68, 104-117. doi:10.1016/j.molcel.2017.09.010

Court, F., Le Boiteux, E., Fogli, A., Müller-Barthélémy, M., Vaurs-Barrière, C., Chautard, E., et al. (2019). Transcriptional Alterations in Glioma Result Primarily from DNA Methylation-independent Mechanisms. Genome Res. 29, 1605-1621. doi:10.1101/gr.249219.119

Cowley, M., Wood, A. J., Böhm, S., Schulz, R., and Oakey, R. J. (2012). Epigenetic Control of Alternative mRNA Processing at the Imprinted Herc3/Nap115 Locus. Nucleic Acids Res. 40, 8917-8926. doi:10.1093/nar/gks654

Dahlet, T., Argüeso Lleida, A., Al Adhami, H., Dumas, M., Bender, A., Ngondo, R. P., et al. (2020). Genome-wide Analysis in the Mouse Embryo Reveals the Importance of DNA Methylation for Transcription Integrity. Nat. Commun. 11, 3153. doi:10.1038/s41467-020-16919-w

Dahlet, T., Truss, M., Frede, U., Al Adhami, H., Bardet, A. F., Dumas, M., et al. (2021). E2F6 Initiates Stable Epigenetic Silencing of Germline Genes during Embryonic Development. Nat. Commun. 12, 3582. doi:10.1038/s41467-02123596-w

Deaton, A. M., and Bird, A. (2011). CpG Islands and the Regulation of Transcription. Genes Dev. 25, 1010-1022. doi:10.1101/gad.2037511

Deaton, A. M., Webb, S., Kerr, A. R. W., Illingworth, R. S., Guy, J., Andrews, R., et al. (2011). Cell Type-specific DNA Methylation at Intragenic CpG Islands in the Immune System. Genome Res. 21, 1074-1086. doi:10.1101/gr.118703.110

De Santa, F., Barozzi, I., Mietton, F., Ghisletti, S., Polletti, S., Tusi, B. K., et al. (2010). A Large Fraction of Extragenic RNA Pol II Transcription Sites Overlap Enhancers. PLoS Biol. 8, e1000384. doi:10.1371/journal.pbio.1000384

Ehrlich, M. (2002). DNA Methylation in Cancer: Too Much, but Also Too Little. Oncogene 21, 5400-5413. doi:10.1038/sj.onc.1205651

Elango, N., and Yi, S. V. (2011). Functional Relevance of CpG Island Length for Regulation of Gene Expression. Genetics 187, 1077-1083. doi:10.1534/genetics. 110.126094

Farcas, A. M., Blackledge, N. P., Sudbery, I., Long, H. K., McGouran, J. F., Rose, N. R., et al. (2012). KDM2B Links the Polycomb Repressive Complex 1 (PRC1) to Recognition of CpG Islands. eLife 1, e00205. doi:10.7554/eLife.00205

Galupa, R., and Heard, E. (2018). X-chromosome Inactivation: A Crossroads between Chromosome Architecture and Gene Regulation. Annu. Rev. Genet. 52, 535-566. doi:10.1146/annurev-genet-120116-024611

Gardiner-Garden, M., and Frommer, M. (1987). CpG Islands in Vertebrate Genomes. J. Mol. Biol. 196, 261-282. doi:10.1016/0022-2836(87)90689-9

Golding, M. C., Magri, L. S., Zhang, L., Lalone, S. A., Higgins, M. J., and Mann, M. R. W. (2011). Depletion of Kcnq1ot1 Non-coding RNA Does Not Affect Imprinting Maintenance in Stem Cells. Development 138, 3667-3678. doi:10. 1242/dev.057778

Greenberg, M. V. C., and Bourc'his, D. (2019). The Diverse Roles of DNA Methylation in Mammalian Development and Disease. Nat. Rev. Mol. Cel Biol. 20, 590-607. doi:10.1038/s41580-019-0159-6

Gruber, A. J., and Zavolan, M. (2019). Alternative Cleavage and Polyadenylation in Health and Disease. Nat. Rev. Genet. 20, 599-614. doi:10.1038/s41576-0190145-z

Hartl, D., Krebs, A. R., Grand, R. S., Baubec, T., Isbel, L., Wirbelauer, C., et al. (2019). CG Dinucleotides Enhance Promoter Activity Independent of DNA Methylation. Genome Res. 29, 554-563. doi:10.1101/gr.241653.118

Hon, G. C., Hawkins, R. D., Caballero, O. L., Lo, C., Lister, R., Pelizzola, M., et al. (2012). Global DNA Hypomethylation Coupled to Repressive Chromatin Domain Formation and Gene Silencing in Breast Cancer. Genome Res. 22, 246-258. doi:10.1101/gr.125872.111
Illingworth, R., Kerr, A., DeSousa, D., Jørgensen, H., Ellis, P., Stalker, J., et al. (2008). A Novel CpG Island Set Identifies Tissue-specific Methylation at Developmental Gene Loci. PLoS Biol. 6, e22. doi:10.1371/journal.pbio.0060022 Illingworth, R. S., Gruenewald-Schneider, U., Webb, S., Kerr, A. R. W., James, K. D., Turner, D. J., et al. (2010). Orphan CpG Islands Identify Numerous Conserved Promoters in the Mammalian Genome. PLoS Genet. 6, e1001134. doi:10.1371/journal.pgen.1001134

Jeziorska, D. M., Murray, R. J. S., De Gobbi, M., Gaentzsch, R., Garrick, D., Ayyub, H., et al. (2017). DNA Methylation of Intragenic CpG Islands Depends on Their Transcriptional Activity during Differentiation and Disease. Proc. Natl. Acad. Sci. USA 114, E7526-E7535. doi:10.1073/pnas.1703087114

Kaikkonen, M. U., Spann, N. J., Heinz, S., Romanoski, C. E., Allison, K. A., Stender, J. D., et al. (2013). Remodeling of the Enhancer Landscape during Macrophage Activation Is Coupled to Enhancer Transcription. Mol. Cel 51, 310-325. doi:10. 1016/j.molcel.2013.07.010

Kanber, D., Berulava, T., Ammerpohl, O., Mitter, D., Richter, J., Siebert, R., et al. (2009). The Human Retinoblastoma Gene Is Imprinted. PLoS Genet. 5, e1000790. doi:10.1371/journal.pgen.1000790

Kim, T.-K., Hemberg, M., Gray, J. M., Costa, A. M., Bear, D. M., Wu, J., et al. (2010). Widespread Transcription at Neuronal Activity-Regulated Enhancers. Nature 465, 182-187. doi:10.1038/nature09033

Krebs, A. R., Dessus-Babus, S., Burger, L., and Schübeler, D. (2014). Highthroughput Engineering of a Mammalian Genome Reveals Building Principles of Methylation States at CG Rich Regions. eLife 3, e04094. doi:10. 7554/eLife.04094

Kulis, M., Heath, S., Bibikova, M., Queirós, A. C., Navarro, A., Clot, G., et al. (2012). Epigenomic Analysis Detects Widespread Gene-Body DNA Hypomethylation in Chronic Lymphocytic Leukemia. Nat. Genet. 44, 1236-1242. doi:10.1038/ng. 2443

Kulis, M., Queirós, A. C., Beekman, R., and Martín-Subero, J. I. (2013). Intragenic DNA Methylation in Transcriptional Regulation, normal Differentiation and Cancer. Biochim. Biophys. Acta Gene Regul. Mech. 1829, 1161-1174. doi:10. 1016/j.bbagrm.2013.08.001

Kumar, D., and Jothi, R. (2020). Bivalent Chromatin Protects Reversibly Repressed Genes from Irreversible Silencing. bioRxiv. doi:10.1101/2020.12.02.406751

Larsen, F., Gundersen, G., Lopez, R., and Prydz, H. (1992). CpG Islands as Gene Markers in the Human Genome. Genomics 13, 1095-1107. doi:10.1016/08887543(92)90024-M

Latos, P. A., Pauler, F. M., Koerner, M. V., Şenergin, H. B., Hudson, Q. J., Stocsits, R. R., et al. (2012). Airn Transcriptional Overlap, but Not its lncRNA Products, Induces Imprinted Igf2r Silencing. Science 338, 1469-1472. doi:10.1126/science. 1228110

Lee, Y., and Rio, D. C. (2015). Mechanisms and Regulation of Alternative PremRNA Splicing. Annu. Rev. Biochem. 84, 291-323. doi:10.1146/annurevbiochem-060614-034316

Lee, S.-M., Lee, J., Noh, K.-M., Choi, W.-Y., Jeon, S., Oh, G. T., et al. (2017). Intragenic CpG Islands Play Important Roles in Bivalent Chromatin Assembly of Developmental Genes. Proc. Natl. Acad. Sci. USA 114, E1885-E1894. doi:10. 1073/pnas.1613300114

Li, W., Notani, D., and Rosenfeld, M. G. (2016). Enhancers as Non-coding RNA Transcription Units: Recent Insights and Future Perspectives. Nat. Rev. Genet. 17, 207-223. doi:10.1038/nrg.2016.4

Logsdon, G. A., Vollger, M. R., and Eichler, E. E. (2020). Long-read Human Genome Sequencing and its Applications. Nat. Rev. Genet. 21, 597-614. doi:10. 1038/s41576-020-0236-x

Maunakea, A. K., Nagarajan, R. P., Bilenky, M., Ballinger, T. J., D’Souza, C., Fouse, S. D., et al. (2010). Conserved Role of Intragenic DNA Methylation in Regulating Alternative Promoters. Nature 466, 253-257. doi:10.1038/ nature 09165

Maupetit-Méhouas, S., Montibus, B., Nury, D., Tayama, C., Wassef, M., Kota, S. K., et al. (2016). Imprinting Control Regions (ICRs) Are Marked by Mono-Allelic Bivalent Chromatin when Transcriptionally Inactive. Nucleic Acids Res. 44, 621-635. doi:10.1093/nar/gkv960

Mikkelsen, T. S., Ku, M., Jaffe, D. B., Issac, B., Lieberman, E., Giannoukos, G., et al. (2007). Genome-wide Maps of Chromatin State in Pluripotent and LineageCommitted Cells. Nature 448, 553-560. doi:10.1038/nature06008

Mochizuki, K., Sharif, J., Shirane, K., Uranishi, K., Bogutz, A. B., Janssen, S. M., et al. (2021). Repression of Germline Genes by PRC1.6 and SETDB1 in the Early 
Embryo Precedes DNA Methylation-Mediated Silencing. Nat. Commun. 12, 7020. doi:10.1038/s41467-021-27345-x

Montibus, B., Cercy, J., Bouschet, T., Charras, A., Maupetit-Méhouas, S., Nury, D., et al. (2021). TET3 Controls the Expression of the H3K27me3 Demethylase Kdm6b during Neural Commitment. Cell. Mol. Life Sci. 78, 757-768. doi:10. 1007/s00018-020-03541-8

Nanavaty, V., Abrash, E. W., Hong, C., Park, S., Fink, E. E., Li, Z., et al. (2020). DNA Methylation Regulates Alternative Polyadenylation via CTCF and the Cohesin Complex. Mol. Cel 78, 752-764. doi:10.1016/j.molcel.2020.03.024

Neri, F., Rapelli, S., Krepelova, A., Incarnato, D., Parlato, C., Basile, G., et al. (2017). Intragenic DNA Methylation Prevents Spurious Transcription Initiation. Nature 543, 72-77. doi:10.1038/nature21373

Onodera, C. S., Underwood, J. G., Katzman, S., Jacobs, F., Greenberg, D., Salama, S. R., et al. (2012). Gene Isoform Specificity through Enhancer-Associated Antisense Transcription. PLOS ONE 7, e43511. doi:10.1371/journal.pone.0043511

Pachano, T., Sánchez-Gaya, V., Ealo, T., Mariner-Faulí, M., Bleckwehl, T., Asenjo, H. G., et al. (2021). Orphan CpG Islands Amplify Poised Enhancer Regulatory Activity and Determine Target Gene Responsiveness. Nat. Genet. 53, 1036-1049. doi:10.1038/s41588-021-00888-x

Proudfoot, N. J. (2011). Ending the Message: Poly(A) Signals Then and Now. Genes Dev. 25, 1770-1782. doi:10.1101/gad.17268411

Santoro, F., Mayer, D., Klement, R. M., Warczok, K. E., Stukalov, A., Barlow, D. P., et al. (2013). Imprinted Igf2r Silencing Depends on Continuous Airn IncRNA Expression and Is Not Restricted to a Developmental Window. Development 140, 1184-1195. doi:10.1242/dev.088849

Saxonov, S., Berg, P., and Brutlag, D. L. (2006). A Genome-wide Analysis of CpG Dinucleotides in the Human Genome Distinguishes Two Distinct Classes of Promoters. Proc. Natl. Acad. Sci. 103, 1412-1417. doi:10.1073/pnas.0510310103

Shah, R. N., Grzybowski, A. T., Elias, J., Chen, Z., Hattori, T., Lechner, C. C., et al. (2021). Re-evaluating the Role of Nucleosomal Bivalency in Early Development. bioRxiv. doi:10.1101/2021.09.09.458948

Shearwin, K., Callen, B., and Egan, J. (2005). Transcriptional Interference - a Crash Course. Trends Genet. 21, 339-345. doi:10.1016/j.tig.2005.04.009

Statham, A. L., Robinson, M. D., Song, J. Z., Coolen, M. W., Stirzaker, C., and Clark, S. J. (2012). Bisulfite Sequencing of Chromatin Immunoprecipitated DNA (BisChIP-Seq) Directly Informs Methylation Status of Histone-Modified DNA. Genome Res. 22, 1120-1127. doi:10.1101/gr.132076.111

Steinhaus, R., Gonzalez, T., Seelow, D., and Robinson, P. N. (2020). Pervasive and CpG-dependent Promoter-like Characteristics of Transcribed Enhancers. Nucleic Acids Res. 48, 5306-5317. doi:10.1093/nar/gkaa223

Takai, D., and Jones, P. A. (2002). Comprehensive Analysis of CpG Islands in Human Chromosomes 21 and 22. Proc. Natl. Acad. Sci. U S A 99, 3740-3745. doi:10.1073/pnas.052410099
Tian, B., and Manley, J. L. (2016). Alternative Polyadenylation of mRNA Precursors. Nat. Rev. Mol. Cel Biol. 18, 18-30. doi:10.1038/nrm.2016.116

Tufarelli, C., Stanley, J. A. S., Garrick, D., Sharpe, J. A., Ayyub, H., Wood, W. G., et al. (2003). Transcription of Antisense RNA Leading to Gene Silencing and Methylation as a Novel Cause of Human Genetic Disease. Nat. Genet. 34, 157-165. doi:10.1038/ng1157

Velasco, G., Hube, F., Rollin, J., Neuillet, D., Philippe, C., Bouzinba-Segard, H., et al. (2010). Dnmt3b Recruitment through E2F6 Transcriptional Repressor Mediates Germ-Line Gene Silencing in Murine Somatic Tissues. Proc. Natl. Acad. Sci. 107, 9281-9286. doi:10.1073/pnas.1000473107

Voigt, P., Tee, W.-W., and Reinberg, D. (2013). A Double Take on Bivalent Promoters. Genes Dev. 27, 1318-1338. doi:10.1101/gad.219626.113

Wachter, E., Quante, T., Merusi, C., Arczewska, A., Stewart, F., Webb, S., et al. (2014). Synthetic CpG Islands Reveal DNA Sequence Determinants of Chromatin Structure. eLife 3, e03397. doi:10.7554/eLife.03397

Williamson, C. M., Ball, S. T., Dawson, C., Mehta, S., Beechey, C. V., Fray, M., et al. (2011). Uncoupling Antisense-Mediated Silencing and DNA Methylation in the Imprinted Gnas Cluster. PLoS Genet. 7, e1001347. doi:10.1371/journal.pgen. 1001347

Wood, A. J., Schulz, R., Woodfine, K., Koltowska, K., Beechey, C. V., Peters, J., et al. (2008). Regulation of Alternative Polyadenylation by Genomic Imprinting. Genes Dev. 22, 1141-1146. doi:10.1101/gad.473408

Zhao, Y., and Garcia, B. A. (2015). Comprehensive Catalog of Currently Documented Histone Modifications. Cold Spring Harb. Perspect. Biol. 7, a025064. doi:10.1101/cshperspect.a025064

Conflict of Interest: The authors declare that the research was conducted in the absence of any commercial or financial relationships that could be construed as a potential conflict of interest.

Publisher's Note: All claims expressed in this article are solely those of the authors and do not necessarily represent those of their affiliated organizations, or those of the publisher, the editors and the reviewers. Any product that may be evaluated in this article, or claim that may be made by its manufacturer, is not guaranteed or endorsed by the publisher.

Copyright (c) 2022 Cain, Montibus and Oakey. This is an open-access article distributed under the terms of the Creative Commons Attribution License (CC $B Y)$. The use, distribution or reproduction in other forums is permitted, provided the original author(s) and the copyright owner(s) are credited and that the original publication in this journal is cited, in accordance with accepted academic practice. No use, distribution or reproduction is permitted which does not comply with these terms. 